Cellular Physiology
and Biochemistry and Biochemistry Published online: March 30,2016

Accepted: February 01, 2016

This article is licensed under the Creative Commons Attribution-NonCommercial-NoDerivatives 4.0 International License (CC BY-NC-ND) (http://www.karger.com/Services/OpenAccessLicense). Usage and distribution for commercial purposes as well as any distribution of modified material requires written permission.
(C) 2016 The Author(s)

\title{
A Case-Control Study Indicates that no Association Exists Between Polymorphisms of IL-33 and IL-1RL1 and Preeclampsia
}

\author{
Xiaoyan Ren ${ }^{a}$ Mingzhen Guo ${ }^{b}$ Caili Liu ${ }^{c}$ Tao Huang ${ }^{d}$ Qiang Lie Mengmeng Han ${ }^{b}$ \\ Weiqing Song ${ }^{f}$ Xiuming Tang ${ }^{g}$ Shiguo Liub

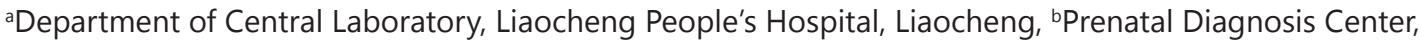 \\ the Affiliated Hospital of Qingdao University, Qingdao, 'Department of Clinical Laboratory, Anyang \\ Maternal and Child Health Care Hospital, Anyang, dDepartment of Clinical Laboratory, Hainan General \\ Hospital, Haikou, 'Department of Andriatry, the Affiliated Hospital of Qingdao University, Qingdao, \\ fDepartment of Clinical Laboratory, Qingdao Municipal Hospital (Group), Qingdao, 9Reproductive \\ Center, the Affiliated Hospital of Qingdao University, Qingdao, China
}

\section{Key Words}

Preeclampsia • IL-33 • IL-1RL1 • Polymorphism • Susceptibility

\begin{abstract}
Background/Aims: Preeclampsia (PE) is a systemic inflammatory response syndrome involving varieties of cytokines, and previous studies have shown that IL-33 and its receptor IL-1RL1 play pivotal roles in the development of it. As a polygenetic hereditary disease, it is necessary to study the gene analysis for PE. Therefore, the present study was to determine whether IL-33 rs3939286 and IL-1RL1 rs13015714 associated with susceptibility to PE in Chinese Han women. Methods: 1,031 PE patients and 1,298 controls were enrolled and the genotyping for rs3939286 in IL-33 and rs13015714 in IL-1RL1 was performed by TaqMan allelic discrimination real-time PCR. Hardy-Weinberg equilibrium (HWE) was examined to ensure the group representativeness and Pearson's chi-square test was used to compare the differences in genetic distributions between the two groups. Results: No significant differences in genotypic and allelic frequencies of the two polymorphisms loci were observed between cases and controls. There were also no significant differences in genetic distributions between mild/ severe and early/late-onset PE and control groups. Conclusion: Although our data suggested that the polymorphisms of IL-33 rs3939286 and IL-1RL1 rs13015714 might not be critical risk factors for PE in Chinese Han women, the results need to be validated in different nations.
\end{abstract}

X. Ren and M. Guo contributed equally to this work.

Xiuming Tang M.D.

and Shiguo Liu M.D. the Affiliated Hospital of Qingdao University, 16 Jiangsu Road, Qingdao, 266003,

(China)

Tel. +8618661807782, E-Mail liushiguo2002@126.com 


\section{Cellular Physiology Cell Physiol Biochem 2016;38:1406-1414 \\ \begin{tabular}{l|l} 
and Biochemistry & DOI: 10.1159/000443083 \\
Published online: March 30, 2016 & $\begin{array}{l}\text { (c) 2016 The Author(s). Published by S. Karger AG, Basel } \\
\text { www.karger.com/cpb }\end{array}$
\end{tabular} \\ Ren et al.: IL-33 and IL-1RLI Polymorphisms and Preeclampsia}

\section{Introduction}

As a most common and severe pregnancy-specific syndrome, preeclampsia (PE) is traditionally characterized by the new onset of hypertension with proteinuria after the $20^{\text {th }}$ gestational week, afflicting 3-5\% of pregnancies [1]. New definitions also include maternal organ dysfunctions such as renal insufficiency, liver damage, neurological or hematological complications and so on and when left untreated, it can be fatal for both the mother and the fetus [1]. PE is still one of the main causes of maternal, fetal, and neonatal morbidity and mortality worldwide with no effective treatment measures except for the termination of pregnancy [1]. Therefore, large numbers of researches have been focused on the etiology of this disorder. However, the exact etiology and pathogenesis remain unclear. Recent studies have suggested that PE is a maternal excessive systemic inflammatory responses involves a Th1/Th2 immune imbalance: normal pregnancy is considered to be a mild inflammatory state with a Th2 predominance, while PE pregnancy has been described as a Th1 dominant pro-inflammatory condition; the Th1 immune bias with participation of varieties of Th1 cytokines including IL-1, IL-2, IL-12, interferon- $\gamma$ (IFN- $\gamma$ ) and so on plays a pivotal role in the development of PE [2-4].

IL-33 is a novel important member of IL-1 cytokine family with strong immunoregulatory functions. As a key pro-inflammatory cytokine, it can enhance Th cell immune responses through combining with its receptor ST2 (suppression of tumorigenicity 2, encoded by IL$1 R L 1$ ) and co-receptor IL-1 receptor accessory protein (IL-1RAcP) [5, 6]. Mainly secreted by endothelial cells, epithelial cells, macrophages and fibroblasts [7], IL-33 can activate dendritic cells (DCs) and then promote the release of Th1 cytokines such as IL-12 and IL-2, both of which can induce the production of IFN- $\gamma$ [8]. IFN- $\gamma$ can inhibit the migration and invasion of cytotrophoblasts and trigger spiral artery modification, which results in placental ischemia and hypoxia, and eventually leads to PE [4, 9]. ST2 belongs to IL-1 receptor super-family and has four isoforms, of which the best characterized are the membrane-bound form ST2L and a soluble variant of ST2 (sST2) [10]. In normal pregnancy, IL-33 binds to ST2L and mainly promotes Th2 responses to maintain the state of immune tolerance to the fetus [11]. While in PE pregnancy, the increased circulating level of sST2 acts as a decoy receptor to regulate the activity of IL-33, which contributes to the Th1 bias observed in this disorder $[12,13]$.

$\mathrm{PE}$ is a complex polygenetic hereditary disease involving both genetic and environmental factors [14] and previous studies have identified many candidate genes associated with susceptibility to it, such as $I L-1[15,16], T N F-\alpha[17,18], I F N-\gamma[19]$ and so on. We therefore hypothesize that $I L-33$ and $I L-1 R L 1$ might play critical roles in pathophysiology of PE. The single nucleotide polymorphisms (SNPs) rs3939286 in $I L-33$ and rs13015714 in IL-1RL1 are two important functional tag SNPs and have been demonstrated in connection with many immune/inflammatory diseases such as inflammatory bowel disease (IBD) [20], rheumatoid arthritis (RA) [21], nasal polyposis (NP) [22] and idiopathic achalasia [23]. In this present study, we attempted to investigate whether IL-33 rs3939286 and IL-1RL1 rs13015714 were associated with risks for PE in Chinese Han women.

\section{Materials and Methods}

\section{Subjects}

1,031 PE patients and 1,298 normal later pregnant women were recruited from Liaocheng People's Hospital, the Affiliated Hospital of Qingdao University, Binzhou Medical University Hospital, Yantai Yuhuangding Hospital, Yantaishan Hospital, Linyi People's Hospital and the Maternal and Child Health Care of Zaozhuang between January 2012 and November 2014. The enrolled subjects were all Chinese Han women who had been hospitalized for the same period, and both groups were age-matched. Basic clinical characteristics like maternal age, gestational week at admission/delivery, systolic/diastolic blood pressure, pregnancy and delivery history, clinical manifestations, and results of laboratory examinations were collected to make a database. The current study was approved by the ethics committee of the Affiliated 


\section{Cellular Physiology Cell Physiol Biochem 2016;38:1406-1414

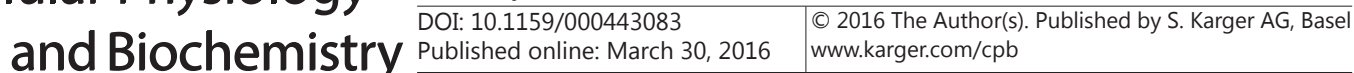 \\ Ren et al.: IL-33 and IL-1RLI Polymorphisms and Preeclampsia}

Hospital of Qingdao University (IRB: QYFY20120107), and all subjects provided their written informed consent with guarantees of confidentiality before participation in the research.

PE was diagnosed on the basis of the onset of hypertension $(\geq 140 / 90 \mathrm{mmHg}$ ) with proteinuria $(\geq$ $0.3 \mathrm{~g} / 24 \mathrm{~h}$, or $\geq 1+$ by dipstick) after the $20^{\text {th }}$ gestational week in a woman with no past history of hypertension, and could be accompanied by upper abdominal discomfort, headache, and blurred vision, according to previously published criteria [24]. The enrolled controls were normal later pregnant women without clinical history of PE, chronic hypertension, heart disease, kidney disorders, diabetes mellitus, hepatic diseases, transfusion, or immunotherapy. They also had no obstetric complications such as premature membrane rupture, placenta previa, or threatened abortion in the present gestation, and those who experienced artificial insemination, twin or multiple pregnancy, and macrosomia should be excluded as well.

\section{Genetic Studies}

Genomic DNA was extracted from $200 \mu$ peripheral venous blood using a DNA extraction kit (Qiagen, Hilden, Germany). The genotyping for the two SNPs loci IL-33 rs3939286 and IL-1RL1 rs13015714 was conducted by the TaqMan allelic discrimination real-time PCR. Taqman probes and primers were synthesized by Applied Biosystems of Life Technologies (New York, USA). The rs3939286 primers were $5^{\prime}$-AGA TAA CAA CAA CCC ACT ACA AGCA-3' (forward) and 5'-CAA CAA CAA ACC ATG GGG ATG TGGA-3' (reverse); rs13015714 primers were $5^{\prime}$-CGG CTA TGG GTT TCC CTT TTC CTTT-3' (forward) and 5'-GTT AAA TAA CAG TTC TGC CAC AAAA-3' (reverse). PCR was conducted in a $25-\mu$ reaction system containing $1.25 \mu \mathrm{l} 20 \times$ SNP Genotyping Assay, $12.5 \mu \mathrm{l} 2 \times$ PCR Master Mix, and $11.25 \mu \mathrm{l}$ DNA and DNase-free water. Amplifications were carried out in a $\mathrm{C}^{1000^{\mathrm{TM}}}$ thermal cycler and $\mathrm{CFX}^{\mathrm{TM}}{ }^{\mathrm{TM}}$ real-time system (Bio-Rad, California, USA) under the following conditions: $95^{\circ} \mathrm{C}$ for $3 \mathrm{~min}$, followed by 45 cycles of $95^{\circ} \mathrm{C}$ for $15 \mathrm{~s}$ and $60^{\circ} \mathrm{C}$ for $1 \mathrm{~min}$. For each cycle, the fluorescent signals from VIC/FAM-labeled probes were detected. The discrimination of genotypes was conducted using Bio-Rad CFX manager 3.0 software.

\section{Statistical Analysis}

Statistical analyses were conducted using statistical software package SPSS 21.0 (SPSS Inc., Chicago, IL). The differences in basic clinical characteristics between case and control groups were identified by Student's $t$-test. Hardy-Weinberg equilibrium (HWE) in both groups was examined using the chi-square test to ensure the representativeness. The comparison in genetic distributions between cases and controls were conducted by Pearson's chi-square test and Fisher's exact test was used when expected values were below 5. The relative risk degree was shown by ORs and $95 \%$ CIs and statistical significance was set at $p<0.05$. Power analysis was performed using the program Power and Sample Size Calculations (PS, Version 3.1.2), considering an alpha of 0.05 .

\section{Results}

\section{Basic Clinical Characteristics}

The differences in basic clinical characteristics between PE and control groups were shown in Table 1 . The two groups were age-matched (cases $30.00 \pm 5.79$ years, controls $30.34 \pm 4.11$ years, $p=0.107$ ), and there were no significant differences in gravidity and the number of abortions between PE patients and controls $(p>0.05)$. However, PE women were admitted and delivered much earlier $(p<0.001)$, and had significantly lower fetal birth weights $(p<0.001)$, higher blood pressure $(p<0.001)$, and elevated levels of white blood cells $(p<0.001)$ and neutrophils $(p=0.001)$ compared to normal pregnant women.

\section{Genotyping Analysis}

The recruited controls in the present study conformed to HWE (rs3939286: $\chi^{2}=1.029$, $p=0.310 ;$ rs13015714: $\chi^{2}=0.005, p=0.945$ ). The genotypic and allelic frequencies in IL-33 rs3939286 and IL-1RL1 rs13015714 between the two groups were summarized in Table 2: there were no significant differences in this two SNP loci between PE patients and controls (rs3939286: for genotype, $p=0.348$, for allele, $\chi^{2}=1.841, p=0.175, \mathrm{OR}=0.831,95 \% \mathrm{CI}$ $0.635-1.086$; rs13015714: for genotype, $\chi^{2}=4.806, p=0.090$, for allele, $\chi^{2}=0.111, p=0.739$, $\mathrm{OR}=0.980,95 \% \mathrm{CI} 0.873-1.101)$. 
Table 1. The basic clinical characteristics of PE and control groups

\begin{tabular}{lcccc}
\hline Characteristics & $\mathrm{PE}(\mathrm{N}=1031)$ & Control(N=1298) & $\mathrm{t}$ & $p$-value \\
\hline Maternal age(years) & $30.00 \pm 5.79$ & $30.34 \pm 4.11$ & -1.612 & 0.107 \\
Gravidity & $2.22 \pm 1.28$ & $2.23 \pm 1.19$ & -0.161 & 0.872 \\
Number of abortion & $0.65 \pm 0.95$ & $0.65 \pm 0.87$ & 0.035 & 0.972 \\
Age of menarche(years) & $13.99 \pm 1.30$ & $14.10 \pm 1.30$ & -1.869 & 0.062 \\
Gestational age at admission(weeks) & $35.10 \pm 5.11$ & $38.91 \pm 2.70$ & -21.086 & $<0.001$ \\
Gestational age at delivery(weeks) & $35.90 \pm 4.83$ & $39.11 \pm 3.28$ & -17.285 & $<0.001$ \\
Fetal birth weight $(\mathrm{kg})$ & $2.61 \pm 0.92$ & $3.40 \pm 0.38$ & -24.479 & $<0.001$ \\
Systolic blood pressure $(\mathrm{mmHg})$ & $158.74 \pm 18.84$ & $113.69 \pm 10.70$ & 68.160 & $<0.001$ \\
Diastolic blood pressure $(\mathrm{mmHg})$ & $103.74 \pm 13.79$ & $73.41 \pm 7.85$ & 62.681 & $<0.001$ \\
White blood cell $\left(\times 10^{9} / \mathrm{L}\right)$ & $9.66 \pm 3.09$ & $9.02 \pm 2.62$ & 5.278 & $<0.001$ \\
Neutrophil $\left(\times 10^{9} / \mathrm{L}\right)$ & $7.45 \pm 4.77$ & $6.86 \pm 3.00$ & 3.421 & 0.001 \\
\hline
\end{tabular}

Table 2. The comparison of genotypic and allelic frequencies between PE and control groups. a: $p$-value of Fisher's exact test

\begin{tabular}{|c|c|c|c|c|c|c|c|c|c|c|c|}
\hline \multirow[b]{2}{*}{ Group } & \multirow[b]{2}{*}{$\mathrm{N}$} & \multicolumn{5}{|c|}{ rs3939286 } & \multicolumn{5}{|c|}{ rs13015714 } \\
\hline & & GG & GA & $\mathrm{AA}$ & G & A & GG & GT & $\mathrm{TT}$ & G & $\mathrm{T}$ \\
\hline PE & 1031 & 923 & 107 & 1 & 1953 & 109 & 329 & 463 & 239 & 1121 & 941 \\
\hline Control & 1298 & 1184 & 113 & 1 & 2481 & 115 & 392 & 640 & 266 & 1424 & 1172 \\
\hline$\chi^{2}$ & & & & & 1.841 & & 4.806 & & & 0.111 & \\
\hline$p$-value & & $0.348^{a}$ & & & 0.175 & & 0.090 & & & 0.739 & \\
\hline OR & & & & & 0.831 & & & & & 0.980 & \\
\hline $95 \% \mathrm{CI}$ & & & & & $0.635-1.0$ & & & & & $0.873-1.10$ & \\
\hline
\end{tabular}

For further investigation of the correlation between IL-33 rs3939286 or IL-1RL1 rs13015714 and PE, we divided PE patients into mild and severe PE subgroups according to the guidelines from the American College of Obstetricians and Gynecologists [25], and then compared the genetic distributions of rs3939286 and rs13015714 in mild or severe PE women with those in normal controls. Table 3 showed that no significant differences in genotypic or allelic frequencies between mild/severe PE patients and controls were observed at any of the two polymorphic sites (mild PE vs. control: rs3939286, for genotype, $p=0.657$, for allele, $\chi^{2}=0.522, p=0.470, \mathrm{OR}=1.217,95 \% \mathrm{CI} 0.714-2.074 ; \mathrm{rs} 13015714$, for genotype, $\chi^{2}=0.677, p=0.713$, for allele, $\chi^{2}<0.001, p=0.989, \mathrm{OR}=0.999,95 \% \mathrm{CI} 0.814-1.224$; severe PE vs. control: rs3939286, for genotype, $p=0.107$, for allele, $\chi^{2}=3.550, p=0.060, \mathrm{OR}=0.764$, 95\%CI 0.577-1.012; rs13015714, for genotype, $\chi^{2}=4.998, p=0.082$, for allele, $\chi^{2}=0.150, p$ $=0.698, \mathrm{OR}=0.976,95 \% \mathrm{CI} 0.861-1.105$ ).

Early-onset PE patients were those diagnosed before the $34^{\text {th }}$ week of gestation, and can be more severely affected than those with later-onset PE [26]. Table 4 showed that there existed a weak association in the genetic distributions of rs3939286 in $I L-33$ between earlyonset PE and control groups (for genotype, $p=0.046$, for allele, $\chi^{2}=4.635, p=0.031$, OR = $0.664,95 \%$ CI $0.457-0.966)$. While no significant differences were found in other comparisons (rs3939286: late-onset PE vs. control, for genotype, $p=0.692$, for allele, $\chi^{2}=0.338, p=0.561$, $\mathrm{OR}=0.913,95 \% \mathrm{CI} 0.670-1.242$; rs13015714: early-onset PE vs. control, for genotype, $\chi^{2}=$ 
Table 3. The comparison of genetic distributions between mild/severe PE and control groups. a: $p$-value of Fisher's exact test

\begin{tabular}{|c|c|c|c|c|c|c|c|c|c|c|c|}
\hline \multirow[b]{2}{*}{ Group } & \multirow[b]{2}{*}{$\mathrm{N}$} & \multicolumn{5}{|c|}{ rs3939286 } & \multicolumn{5}{|c|}{ rs13015714 } \\
\hline & & GG & GA & AA & G & A & GG & GT & TT & G & $\mathrm{T}$ \\
\hline Mild PE & 218 & 202 & 16 & 0 & 420 & 16 & 69 & 101 & 48 & 239 & 197 \\
\hline Control & 1298 & 1184 & 113 & 1 & 2481 & 115 & 392 & 640 & 266 & 1424 & 1172 \\
\hline$\chi^{2}$ & & & & & 0.522 & & 0.677 & & & $<0.001$ & \\
\hline$p$-value & & 0.657 a & & & 0.470 & & 0.713 & & & 0.989 & \\
\hline OR & & & & & 1.217 & & & & & 0.999 & \\
\hline $95 \% \mathrm{CI}$ & & & & & $0.714-2 . c$ & & & & & $0.814-1.2$ & \\
\hline Severe PE & 813 & 721 & 91 & 1 & 1533 & 93 & 260 & 362 & 191 & 882 & 744 \\
\hline Control & 1298 & 1184 & 113 & 1 & 2481 & 115 & 392 & 640 & 266 & 1424 & 1172 \\
\hline$\chi^{2}$ & & & & & 3.550 & & 4.998 & & & 0.150 & \\
\hline$p$-value & & $0.107^{a}$ & & & 0.060 & & 0.082 & & & 0.698 & \\
\hline OR & & & & & 0.764 & & & & & 0.976 & \\
\hline $95 \% \mathrm{CI}$ & & & & & $0.577-1.0$ & & & & & $0.861-1.1$ & \\
\hline
\end{tabular}

Table 4. The comparison of genetic distributions between early/late-onset PE and control groups. a: $p$-value of Fisher's exact test

\begin{tabular}{|c|c|c|c|c|c|c|c|c|c|c|c|}
\hline \multirow[b]{2}{*}{ Group } & \multirow[b]{2}{*}{$\mathrm{N}$} & \multicolumn{5}{|c|}{ rs3939286 } & \multicolumn{5}{|c|}{ rs 13015714} \\
\hline & & GG & GA & $\mathrm{AA}$ & G & A & GG & GT & TT & G & $\mathrm{T}$ \\
\hline Early-onset PE & 299 & 260 & 39 & 0 & 559 & 39 & 98 & 137 & 64 & 333 & 265 \\
\hline Control & 1298 & 1184 & 113 & 1 & 2481 & 115 & 392 & 640 & 266 & 1424 & 1172 \\
\hline$\chi^{2}$ & & & & & 4.635 & & 1.231 & & & 1.360 & \\
\hline$p$-value & & $0.046^{\mathrm{a}}$ & & & 0.031 & & 0.540 & & & 0.712 & \\
\hline OR & & & & & 0.664 & & & & & 1.034 & \\
\hline $95 \% \mathrm{CI}$ & & & & & $.457-0.9$ & & & & & $.865-1.237$ & \\
\hline Late-onset PE & 693 & 627 & 65 & 1 & 1319 & 67 & 218 & 307 & 168 & 743 & 643 \\
\hline Control & 1298 & 1184 & 113 & 1 & 2481 & 115 & 392 & 640 & 266 & 1424 & 1172 \\
\hline$\chi^{2}$ & & & & & 0.338 & & 5.527 & & & 0.566 & \\
\hline$p$-value & & $0.692^{a}$ & & & 0.561 & & 0.063 & & & 0.452 & \\
\hline OR & & & & & 0.913 & & & & & 0.951 & \\
\hline $95 \% \mathrm{CI}$ & & & & & $670-1.2$ & & & & & $.834-1.084$ & \\
\hline
\end{tabular}

1.231, $p=0.540$, for allele, $\chi^{2}=1.360, p=0.712$, OR $=1.034,95 \%$ CI $0.865-1.237$; late-onset PE vs. control, for genotype, $\chi^{2}=5.527, p=0.063$, for allele, $\chi^{2}=0.566, p=0.452$, OR $=0.951$, 95\%CI 0.834-1.084).

\section{Discussion}

$\mathrm{PE}$ is one of the most common and severe obstetric complications and remains a leading cause of maternal, fetal and neonatal morbidity and mortality worldwide, especially in lowincome and middle-income countries [27]. If were not given timely diagnosis and treatment, PE patients could experience some severe complications such as eclampsia, kidney failure, 


\section{Cellular Physiology Cell Physiol Biochem 2016;38:1406-1414 \\ \begin{tabular}{cc|c|} 
DOI: 10.1159/000443083 & $\begin{array}{l}\text { @ 2016 The Author(s). Published by S. Karger AG, Basel } \\
\text { www.karger.com/cpb }\end{array}$ \\
\hline and Biochemistry
\end{tabular}

stroke and so on, which can all put to death [28]. Moreover, children born to PE mothers can have increased risks of cerebral palsy and bronchopulmonary dysplasia arising from premature delivery and tend to be much smaller for the gestational age $[29,30]$. However, the precise etiology and pathogenesis of PE need to be further elucidated. Previous studies have been indicated that the development of PE relates to inflammatory responses, immune imbalance, placental ischemia and hypoxia, oxidative stress, and hereditary factors $[2-4,14$, 31-34], and the role of Th1/Th2 imbalance in PE is becoming increasingly important.

Normal successful pregnancy is described as a state of Th2 dominant mild inflammatory responses secondary to the presence of the placenta, which helps create an immune-tolerant environment for the prevention of fetal rejection. By contrast, PE pregnancy is considered to be an excessive maternal pro-inflammatory state with Th1 predominance, which involves a series of Th1 cytokine immune responses [2]. As one of the most important early proinflammatory cytokines, IL-33 plays a key role in promoting the development of Th1 responses. Primarily secreted by endothelial/epithelial cells and macrophages [7], IL-33 can activate DCs to release Th1 cytokines such as IL-12 and IL-2, both of which can induce the production of IFN- $\gamma$ [8]. For one thing, IL-12 can promote Th0 cells to proliferate and differentiate into Th 1 cells, as well as induce IFN- $\gamma$ release from activated $\mathrm{T}$ and natural killer (NK) cells; for another, IL-2 can activate NK/NKT cells and then promote the production of IFN- $\gamma$ [8]. IFN- $\gamma$ can enhance the cytotoxic potential of NK cells, leading to the induction of vascular spasms of placenta tissue; it can also inhibit the migration and invasion of cytotrophoblasts, and trigger spiral artery modification [4], which can result in placental ischemia and hypoxia, the release of angiogenic and inflammatory factors, and maternal endothelial damage, eventually leads to occurrence of PE [4]. The IL-33 receptor ST2 has two important isoforms of ST2L and SST2. In normal pregnancy, IL-33 combines with ST2L and primarily activates Th2 immune responses to maintain the state of immune tolerance to the fetus [11]. While in PE pregnancy, SST2 acts as a decoy receptor to regulate the activity of IL33, which contributes to the Th1 bias observed in this disorder. Both Ingrid Granne [12] and Tamara Stampalija have demonstrated that the circulating level of sST2 was significantly elevated in PE patients compared to normal pregnant women.

As PE is a polygenetic hereditary disease and previous studies have been indicated that many cytokine genes are associated with susceptibility to it such as VEGF [35, 36], NLRP1 [37], IL-1 [15, 16], TNF- $\alpha[17,18], I F N-\gamma[19]$ and so on. Therefore in the present study we investigated whether IL-33 rs3939286 and IL-1RL1 rs13015714 play pivotal roles in the development of PE. Our current study found no significant differences in genetic distributions of the rs3939286 in $I L-33$ and rs13015714 in $I L-1 R L 1$ between PE patients and controls. We further divided the PE patients into mild/severe and early/late-onset subgroups and there were also no significant differences. Our results suggest that the two SNP loci rs3939286 and rs13015714 might not associate with risks for PE in Chinese Han women. To the best of our knowledge, we are the first worldwide to study the correlation between IL-33 rs3939286 and IL-1RL1 rs13015714 and PE susceptibility in Chinese Han Population. But this should be verified in different races and regions. However, previous studies have demonstrated that the two SNPs are in connection with risks for some other diseases. For instance, Anna Latiano and his colleagues [20] have found that the IL-33 rs3939286 associates with risks for both Crohn's disease (CD) and ulcerative colitis (UC), while IL-1RL1 rs13015714 contributes to the risk of CD in an Italian patients cohort of adult and pediatrics. Buysschaert ID et al. [22] conducted a two-stage study, suggesting that the rs3939286 played a significant role in the pathogenesis of NP.

There are many reasons that could explain our negative results. As PE is a polygenetic hereditary disease, it is conceivable that one or even several SNP loci defect might not cause changes of gene expression and function. Secondly, environmental factors such as diet, obesity, stress and so on could make influence on the occurrence of PE. Moreover, the differences from race and region are likely to affect the results. In addition, our results were also limited by the sample size of the present study (the post-hoc power calculations for rs3939286 and rs13015714 are $13.7 \%$ and 5.7\% respectively). Finally, we only investigated 


\section{Cellular Physiology Cell Physiol Biochem 2016;38:1406-1414 \\ \begin{tabular}{c|c|c|} 
DOI: 10.1159/000443083 & $\begin{array}{l}\text { O 2016 The Author(s). Published by S. Karger AG, Basel } \\
\text { www.karger.com/cpb }\end{array}$
\end{tabular} \\ Ren et al.: IL-33 and IL-1RLI Polymorphisms and Preeclampsia}

two SNP loci of $I L-33$ and $I L-1 R L 1$, and did not analyze the interaction with environmental risk factors and comorbidity. Therefore, larger-scale functional and genetic studies investigating different genes in patients from multiple races and regions are necessary to discover new PE candidate genes for susceptibility and to gain further insights into its pathogenesis.

\section{Acknowledgments}

We are grateful to all participants who have made the completion of this study.

\section{Disclosure Statement}

The authors report no conflicts of interest. The authors alone are responsible for the content and writing of the paper.

\section{References}

1 Mol BW, Roberts CT, Thangaratinam S, Magee LA, de Groot CJ, Hofmeyr GJ: Pre-eclampsia: Lancet 2015; pii:S0140-6736(15)00070-7.

2 Perez-Sepulveda A, Torres MJ, Khoury M, Illanes SE: Innate immune system and preeclampsia. Front Immunol 2014;5:244.

3 Darmochwal-Kolarz D, Oleszczuk J: The critical role of th17 cells, treg cells and co-stimulatory molecules in the development of pre-eclampsia. Dev Period Med 2014;18:141-147.

4 Laresgoiti-Servitje E, Gomez-Lopez N, Olson DM: An immunological insight into the origins of preeclampsia. Hum Reprod Update 2010;16:510-524.

5 Xu D, Jiang HR, Kewin P, Li Y, Mu R, Fraser AR, Pitman N, Kurowska-Stolarska M, McKenzie AN, McInnes IB, Liew FY: Il-33 exacerbates antigen-induced arthritis by activating mast cells. Proc Natl Acad Sci USA 2008;105:10913-10918.

6 Palmer G, Talabot-Ayer D, Lamacchia C, Toy D, Seemayer CA, Viatte S, Finckh A, Smith DE, Gabay C: Inhibition of interleukin-33 signaling attenuates the severity of experimental arthritis. Arthritis Rheum 2009;60:738-749.

7 De la Fuente M, MacDonald TT, Hermoso MA: The il-33/st2 axis: Role in health and disease. Cytokine Growth Factor Rev 2015;26:615-623.

8 Hamzaoui K, Bouali E, Hamzaoui A: Interleukin-33 and behcet disease: Another cytokine among others. Hum Immunol 2015;76:301-306.

9 Hu Y, Dutz JP, MacCalman CD, Yong P, Tan R, von Dadelszen P: Decidual nk cells alter in vitro first trimester extravillous cytotrophoblast migration: A role for ifn-gamma. J Immunol 2006;177:8522-8530.

10 Kakkar R, Lee RT: The il-33/st2 pathway: Therapeutic target and novel biomarker. Nat Rev Drug Discov 2008; 7:827-840.

11 Gajardo Carrasco T, Morales RA, Perez F, Terraza C, Yanez L, Campos-Mora M, Pino-Lagos K: Alarmin' immunologists: Il-33 as a putative target for modulating t cell-dependent responses. Front Immunol 2015;6:232.

12 Granne I, Southcombe JH, Snider JV, Tannetta DS, Child T, Redman CW, Sargent IL: St2 and il-33 in pregnancy and pre-eclampsia. PLoS One 2011;6:e24463.

13 Stampalija T, Chaiworapongsa T, Romero R, Chaemsaithong P, Korzeniewski SJ, Schwartz AG, Ferrazzi EM, Dong Z, Hassan SS: Maternal plasma concentrations of sst2 and angiogenic/anti-angiogenic factors in preeclampsia. J Matern Fetal Neonatal Med 2013;26:1359-1370.

14 Lardoeyt R, Vargas G, Lumpuy J, Garcia R, Torres Y: Contribution of genome-environment interaction to pre-eclampsia in a havana maternity hospital. MEDICC Rev 2013;15:22-29.

15 Li J, Liu M, Zong J, Tan P, Wang J, Wang X, Ye Y, Liu S, Liu X: Genetic variations in il1a and il1rn are associated with the risk of preeclampsia in chinese han population. Sci Rep 2014;4:5250. 


\section{Cellular Physiology Cell Physiol Biochem 2016;38:1406-1414 \begin{tabular}{l|l|l} 
DOI: 10.1159/000443083 & $\begin{array}{l}\text { C } 2016 \text { The Author(s). Published by S. Karger AG, Basel } \\
\text { www.karger.com/cpb }\end{array}$
\end{tabular} \\ Ren et al.: IL-33 and IL-1RL1 Polymorphisms and Preeclampsia}

16 Wang X, Jiang F, Liang Y, Xu L, Li H, Liu Y, Liu S, Ye Y: Interleukin-1beta-31c/t and -511t/c polymorphisms were associated with preeclampsia in chinese han population. PLoS One 2014;9:e106919.

17 Zubor P, Dokus K, Zigo I, Skerenova M, Pullmann R, Danko J: Tnf alpha g308a gene polymorphism has an impact on renal function, microvascular permeability, organ involvement and severity of preeclampsia. Gynecol Obstet Invest 2014;78:150-161.

18 Naderi M, Yaghootkar H, Tara F, Tavakkol Afshari J, Farid Hosseini R, Ghayour Mobarhan M, Shapouri Moghadam A, Mirteimouri M, Tara SM: Tumor necrosis factor-alpha polymorphism at position -238 in preeclampsia. Iran Red Crescent Med J 2014;16:e11195.

19 Pinheiro MB, Gomes KB, Ronda CR, Guimaraes GG, Freitas LG, Teixeira-Carvalho A, Martins-Filho OA, Dusse LM: Severe preeclampsia: Association of genes polymorphisms and maternal cytokines production in brazilian population. Cytokine 2015;71:232-237.

20 Latiano A, Palmieri O, Pastorelli L, Vecchi M, Pizarro TT, Bossa F, Merla G, Augello B, Latiano T, Corritore G, Settesoldi A, Valvano MR, D'Inca R, Stronati L, Annese V, Andriulli A: Associations between genetic polymorphisms in il-33, il1r1 and risk for inflammatory bowel disease. PLoS One 2013;8:e62144.

21 Lopez-Mejias R, Genre F, Remuzgo-Martinez S, Robustillo-Villarino M, Garcia-Bermudez M, Llorca J, Corrales A, Gonzalez-Juanatey C, Ubilla B, Miranda-Filloy JA, Mijares V, Pina T, Blanco R, Alegre-Sancho JJ, Ramirez Huaranga MA, Minguez Sanchez MD, Tejera Segura B, Ferraz-Amaro I, Vicente E, Carmona FD, Castaneda S, Martin J, Gonzalez-Gay MA: Protective role of the interleukin 33 rs3939286 gene polymorphism in the development of subclinical atherosclerosis in rheumatoid arthritis patients. PLoS One 2015;10:e0143153.

22 Buysschaert ID, Grulois V, Eloy P, Jorissen M, Rombaux P, Bertrand B, Collet S, Bobic S, Vlaminck S, Hellings PW, Lambrechts D: Genetic evidence for a role of il33 in nasal polyposis. Allergy 2010;65:616-622.

23 Latiano A, Palmieri O, Bossa F, Latiano T, Corritore G, De Santo E, Martino G, Merla A, Valvano MR, Cuttitta A, Mazza T, Annese V, Andriulli A: Impact of genetic polymorphisms on the pathogenesis of idiopathic achalasia: Association with il33 gene variant. Hum Immunol 2014;75:364-369.

24 Report of the national high blood pressure education program working group on high blood pressure in pregnancy. Am J Obstet Gynecol 2000;183:S1-S22.

25 Bulletins--Obstetrics ACoP: Acog practice bulletin. Diagnosis and management of preeclampsia and eclampsia. Number 33, january 2002. Obstet Gynecol 2002;99:159-167.

26 Alvarez-Fernandez I, Prieto B, Rodriguez V, Ruano Y, Escudero AI, Alvarez FV: New biomarkers in diagnosis of early onset preeclampsia and imminent delivery prognosis. Clin Chem Lab Med 2014;52:1159-1168.

27 Saleem S, McClure EM, Goudar SS, Patel A, Esamai F, Garces A, Chomba E, Althabe F, Moore J, Kodkany B, Pasha O, Belizan J, Mayansyan A, Derman RJ, Hibberd PL, Liechty EA, Krebs NF, Hambidge KM, Buekens P, Carlo WA, Wright LL, Koso-Thomas M, Jobe AH, Goldenberg RL, Global Network Maternal Newborn Health Registry Study I: A prospective study of maternal, fetal and neonatal deaths in low- and middle-income countries. Bull World Health Organ 2014;92:605-612.

28 Souza JP, Gulmezoglu AM, Vogel J, Carroli G, Lumbiganon P, Qureshi Z, Costa MJ, Fawole B, Mugerwa Y, Nafiou I, Neves I, Wolomby-Molondo JJ, Bang HT, Cheang K, Chuyun K, Jayaratne K, Jayathilaka CA, Mazhar SB, Mori R, Mustafa ML, Pathak LR, Perera D, Rathavy T, Recidoro Z, Roy M, Ruyan P, Shrestha N, Taneepanichsku S, Tien NV, Ganchimeg T, Wehbe M, Yadamsuren B, Yan W, Yunis K, Bataglia V, Cecatti JG, Hernandez-Prado B, Nardin JM, Narvaez A, Ortiz-Panozo E, Perez-Cuevas R, Valladares E, Zavaleta N, Armson A, Crowther C, Hogue C, Lindmark G, Mittal S, Pattinson R, Stanton ME, Campodonico L, Cuesta C, Giordano D, Intarut N, Laopaiboon M, Bahl R, Martines J, Mathai M, Merialdi M, Say L: Moving beyond essential interventions for reduction of maternal mortality (the who multicountry survey on maternal and newborn health): A cross-sectional study. Lancet 2013;381:1747-1755.

29 Hansen AR, Barnes CM, Folkman J, McElrath TF: Maternal preeclampsia predicts the development of bronchopulmonary dysplasia. J Pediatr 2010;156:532-536.

30 Strand KM, Heimstad R, Iversen AC, Austgulen R, Lydersen S, Andersen GL, Irgens LM, Vik T: Mediators of the association between pre-eclampsia and cerebral palsy: Population based cohort study. BMJ 2013;347:f4089.

31 Cindrova-Davies T: Gabor than award lecture 2008: Pre-eclampsia - from placental oxidative stress to maternal endothelial dysfunction. Placenta 2009;30:S55-65. 


\section{Cellular Physiology Cell Physiol Biochem 2016;38:1406-1414

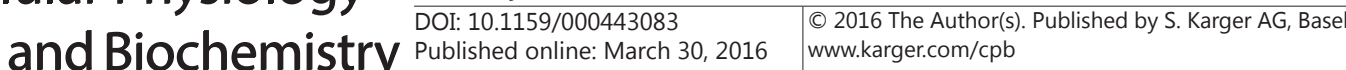 \\ Ren et al.: IL-33 and IL-1RL1 Polymorphisms and Preeclampsia}

32 Huang QT, Chen JH, Hang LL, Liu SS, Zhong M: Activation of par-1/nadph oxidase/ros signaling pathways is crucial for the thrombin-induced sflt-1 production in extravillous trophoblasts: Possible involvement in the pathogenesis of preeclampsia. Cell Physiol Biochem 2015;35:1654-1662.

33 Jia RZ, Ding GC, Gu CM, Huang T, Rui C, Wang YX, Lu Q: Cdx2 enhances htr-8/svneo trophoblast cell invasion by altering the expression of matrix metalloproteinases. Cell Physiol Biochem 2014;34:628-636.

34 Shen Z, Wu Y, Chen X, Chang X, Zhou Q, Zhou J, Ying H, Zheng J, Duan T, Wang K: Decreased maternal serum 2-methoxyestradiol levels are associated with the development of preeclampsia. Cell Physiol Biochem 2014;34:2189-2199.

35 Cheng D, Hao Y, Zhou W, Ma Y: Vascular endothelial growth factor +936c/t, -634g/c, -2578c/a, and -1154g/ a polymorphisms with risk of preeclampsia: A meta-analysis. PLoS One 2013;8:e78173.

36 Procopciuc LM, Caracostea G, Zaharie G, Stamatian F: Maternal/newborn vegf-c936t interaction and its influence on the risk, severity and prognosis of preeclampsia, as well as on the maternal angiogenic profile. J Matern Fetal Neonatal Med 2014;27:1754-1760.

37 Pontillo A, Reis EC, Bricher PN, Vianna P, Diniz S, Fernandes KS, Chies JA, Sandrim V: Nlrp1 1155h polymorphism is a risk factor for preeclampsia development. Am J Reprod Immunol 2015;73:577-581. 